\title{
Identifying the Sources of Academic Stress and Coping Strategies in New Nursing Students
}

\author{
Nur Aini \\ Departement of Nursing, Faculty of Health Science, University of Muhammadiyah Malang \\ Jalan Bendungan Sutami 188A Malang Indonesia 65145 \\ Corresponding author:aini_anindya@yahoo.com
}

\begin{abstract}
Backgrounds: Differences between the education system of senior high school and college can cause stress on students, especially for new students. This problem requires students looking for ways to address these issues by using a coping mechanism. Objectives: This study aims to determine the source of the cause of academic stress in nursing freshman and how coping mechanism or coping strategies used by them. Methods: The study was a descriptive analytic design. The samples were 110 nursing freshman taken by simple random sampling technique. The research instrument used Coping Strategies Inventory (CSI). The data were analyzed by statistic descriptive and with Mann Whitney test. Results: The results showed $56(51 \%)$ of students experiencing low academic stress and high stress on 54 students (49\%). The highest cause of stress was academic factors and the lowest was environmental factors. The majority of the coping mechanism at the level of moderately adequate. Coping strategies that have used are problem solving and problem focused engagement. Conclusion : Based on the findings, the recommendations such as teach stress management, counseling, socialization of how learning programs that will be undertaken by the new nursing students for college later and reduce the academic burden on first semester because for this semester students is still in the adaptation stage.
\end{abstract}

Keywords: academic stress, coping mechanism, coping strategies, nursing students.

\section{INTRODUCTION}

The world of universities have a challenge for anyone who entered it, especially for new students. This is due to differences in education systems between high school and college. When the high school, with regularly scheduled learning process, teachers teach in accordance with the specified schedule. In contrast to the current study, the learning time becomes independent and flexible. Students must organize their own activities, more assignments, and limited interaction time with lecturer because not every day lecturer can be found on the campus. These conditions will cause stress on students, especially for new students. Usually the stress will be experienced in the first year of study and at the end of the semester.

World health education cannot be separated from the stress and demands. Excessive workload, causing the students have little free time to relax and even sometimes cause serious sleep disorder (Shaikh et al, 2004), Professional education such as nursing have full experience of stress and this often affects the physical and mental health. Nursing students are prone to the incidence of stressful compared to other students, because they are often faced with a situation that requires them to take responsibility for the life and death of others, new social spheres, difficulty adjusting to the academic expectations, the duration of the study, many theories that must be mastered, and learn with people of different cultures and beliefs ( Al-Barrak et al, 2011; Singh \& Kohli, 2015; Hirsch et al, 2015) if students are not able to adapt to the stress experienced, it will affect the academic performance and overall health condition. 
Some research suggests that nursing students are prone to stress than students of other majors. The first-year nursing students in India experience severe stress $51.6 \%$ and $46.7 \%$ moderate stress (Prasad et al, 2013). nursing students of Jimma University in Ethiopia, 47.7\% had stress with stress is the dominant source of intrapersonal factors $(54.9 \%)$ and interpersonal factors $(36.3 \%)$ (Shiferaw et al, 2015). While the sources of stress in 146 nursing students in Brazil is a professional education, lack of knowledge and lack of free time. 61 nursing students in the Philippines, the majority experienced moderate stress, the main source of stress is the number of tasks (Labrague, 2013; Shiferaw et al, 2015; Hirsch et al, 2015). Results of a preliminary study conducted on 15 new nursing students, in October $2015,85 \%$ of the causes of stress experienced by students is because of the many duties of lectures and adaptation to the new environment. Coping strategies used by the majority of new students in overcoming this stress is to seek information from seniors, study groups, relieve stress by watching TV, and pray, sometimes cross their minds to quit college and ditching.

Lazarus and Folkman (1984) defined stress as a relationship involving an individual and environment, which is evaluated by the individual as demanding or beyond his or her available resources. Stress Also been Considered to be a situation and the state of tension it generates in an individual as a result of the persons perception of that situation as threatening to his or her existence, and there is a gap between the demands of the environment and the individual's ability to meet the rated potential harmful, threatening, harassing and uncontrolled or exceed the individual's ability to perform coping. Stress involves physical and emotional responses that we do to face a threatening event (Boyd, 2008; Al-Zayyat et al, 2014; Abasimi et al, 2015).

Normal stress experienced by each individual and become an integral part of life. In modern life, stress can be a pressure, but also can make a person to do better. Stress makes a person who experienced it think and work hard to solve a problem or challenge in life as a form of adaptation responses to stay afloat (Abasimi et al, 2015). Stress could be positive and negative. Severe stress is not necessarily bad for someone, may actually be motivated to try harder. In conclusion nothing is stressful, but become stressful depending on the perception and interpretation of individual.

Stress experienced by the students included in the category of academic stress. Academic stress is the response that came with too many demands and tasks that must be undertaken by students. Students in the academic life will face the problem of social, emotional, physical and family that can interfere with learning and academic performance. Student response to the stressor will vary. Some students may be frustrated, while others see a stressor as a challenge to be able to try harder. Students in transition from their late teens to the early adulthood. The physiological and hormonal changes, resulting in emotionally unstable students in dealing with problems, so that students tend to be more susceptible to stress. Stress experienced by students, requiring them to seek ways or using coping strategies in order to survive or to face problems (Abasimi et al, 2015; Kaneko \& Momino, 2015).

Coping is defined as an individual's capacity to face and adapt to stressful situations, an ability that allows people to react to behavior, thoughts and emotion caused by such events (Hirsch et al, 2015). Coping has been viewed as a stabilizing factor that may assist individual in psychosocial adaptation during stressful events and influence an individual experience of stress. Strategies or coping mechanism used by individuals to help protect against feelings of helplessness and anxiety. However, sometimes a coping mechanism that individuals distorted and no longer able to help in the face of a stressor (Kumar,\& Bhukar, 2013; Bamuhair et al, 2015).

The purpose of this study is to determine the source of the cause of academic stress in nursing freshman and how the strategy or coping mechanism they use. Although in some countries the existing previous research on academic stress, but there are differences in socio demographic background and the curriculum or teaching methods used at each institution. 


\section{METHOD}

The study was a descriptive analytic design, the researchers wanted to portray the factors that become a source of academic stressors on new students and how they do strategies or coping mechanism to deal with such stress. The population in this study is new students of undergraduate nursing program of University of Muhammadiyah Malang (UMM) 2015 generation that consist of 150 students, while the number of 110 samples were taken by simple random sampling technique. The study was conducted in May 2016. Research variables such as the source or cause of academic stress and coping mechanism.

Ethical approval was obtained from authorities of University of Muhammadiyah Malang. While written informed consent was obtained from participants. Participants were assured of their right to privacy, and data were kept strictly confidential. No names or personal details were included, and each participant was given an identification code.

The research instrument using a coping mechanism "Coping Strategies Inventory (CSI)" designed by David L. Tobin consisting of 72 questions in a five-item Likert format. The subscales of the CSI was accessed using scale primary, secondary and tertiary scale (Table 1). The score obtained in the questionnaire for each subtest is further converted into percentage and categorized depending on the score listed below (Tobin, 2001; Jobson \& Subhashini, 2016) :

Table 1 Subscales of Coping Strategies Inventory (CSI) Questionnaire

\begin{tabular}{ll}
\hline \multicolumn{1}{c}{ Subscales } & \multicolumn{1}{c}{ Component } \\
\hline Primary subscales & $\begin{array}{l}\text { Problem solving, cognitive restructuring, express emotions, social support, } \\
\text { problem avoidance, wishful thinking, social withdrawal and self-critics }\end{array}$ \\
\hline Secondary subscales & Problem focused engagement (problem solving and cognitive restructuring). \\
& Emotion focused engagement (social support and express emotions) \\
& Problem focused disengagement (problem avoidance and wishful thinking) \\
& Emotion focused disengagement (social withdrawal and self-criticism) \\
\hline Tertiary subscales & Engagement \\
& Disengagement \\
\hline
\end{tabular}

While the instruments adopted from Yumba (2010) stress comprising aspects: 1). Stress due to relationships with others, 2). Stress due to personal factors, 3). Stress due to academic and 4). Stress due to environmental factors. The higher scores indicating greater levels of stress.

The data were analyzed descriptively to analyze demographic data, a source of stress and coping mechanism subscales consisting of primary, secondary and tertiary subscales. The descriptive statistics used were mean, median, standard deviation, range, frequency and percentage. The inferential test, Mann Whitney test was used to analyze the differences in the level of stress and coping mechanism based on demographic characteristics with $\alpha=0.05$.

\section{RESULTS AND DISCUSSION}

\section{Demographic characteristics}

Based the demographic variables of the study, the majority of the students were female $(\mathrm{n}=89,81 \%)$, attend the college because of her own desire $(\mathrm{n}=91,83 \%)$, live in boarding house $(\mathrm{n}=83,75 \%)$, high school science majors $(\mathrm{n}=67,61 \%)$ and the mean age of students was 18 years old (standard deviation $=0.6$ ).

\section{Level of Stress}

The majority of the stress level is at a low level $(\mathrm{n}=56,51 \%$, mean $=94, \mathrm{SD}=10.8$ and range of scores 69-133). Based on the source of stress / stressor, then the highest stress due to academic factors (mean $=30.2 ; \mathrm{SD}=4.75)$ and the lowest is a source of stress environmental 
factors $($ mean $=17.3 ; \mathrm{SD}=4.08)$ (Table 2 and 3$)$. The results of the stress level differences based on demographic characteristics can be seen in (Table 4), statistically no significant difference in the level of stress based on demographic characteristics ( $p$ value $=0.96 ; 0.86 ; 0.66$ and $0.63>\alpha=0.05)$.

Table 2 Level of Stress

\begin{tabular}{lcccccc}
\hline \multirow{2}{*}{ Variables } & Mean & \multicolumn{2}{c}{ Score } & SD & \multicolumn{2}{c}{ Level * } \\
\cline { 2 - 3 } \cline { 5 - 6 } & & Min & Max & & High & Low \\
\hline Stress & 94 & 69 & 133 & 10.8 & $54(49 \%)$ & $56(51 \%)$ \\
\hline Note: * cut of point-based mean value $(>$ mean $=$ high, $<$ mean $=$ low $)$ &
\end{tabular}

Table 3 Stressors of Stress

\begin{tabular}{lccc}
\hline \multicolumn{1}{c}{ Stressor } & Mean & SD & Rank \\
\hline Relationships with others & 19.2 & 4.40 & 3 \\
\hline Personal factors & 273 & 4.33 & 2 \\
\hline Academic factors & 30.2 & 4.75 & 1 \\
\hline Environmental factor & 17.3 & 4.08 & 4 \\
\hline
\end{tabular}

Table 4 Relationship Demographic Characteristics with Stress Level and Coping Mechanism

\begin{tabular}{|c|c|c|c|c|c|c|c|}
\hline \multirow[t]{2}{*}{ Variables } & \multicolumn{3}{|c|}{ Level of stress } & \multicolumn{4}{|c|}{ Level of coping mechanism } \\
\hline & High & Low & $\begin{array}{c}\text { P- } \\
\text { value }\end{array}$ & Inadequate & $\begin{array}{c}\text { Moderately } \\
\text { adequate }\end{array}$ & Adequate & P-value \\
\hline Gender & & & 0.96 & & & & .737 \\
\hline Man & $11(52.3 \%)$ & $10(47.7 \%)$ & & 0 & $20(95.23 \%)$ & $1(4.77 \%)$ & \\
\hline Woman & $43(48.31 \%)$ & $46(51.69 \%)$ & & $3(3.37 \%)$ & $81(91.01 \%)$ & $5(5.62 \%)$ & \\
\hline Reason of lecture & & & 0.86 & & & & 0.534 \\
\hline Own desire & $42(46.15 \%)$ & $49(53.85 \%)$ & & $3(3.3 \%)$ & $83(91.20 \%)$ & $5(5.5 \%)$ & \\
\hline Prompting parents & $12(63.15 \%)$ & $7(36.85 \%)$ & & 0 & $18(94.73 \%)$ & $1(5.27 \%)$ & \\
\hline Living status & & & 0.66 & & & & 0.186 \\
\hline With parents & $14(51.9 \%)$ & $13(48.1 \%)$ & & 0 & $26(96.3 \%)$ & $1(3.7 \%)$ & \\
\hline Boarding house & $40(48.31 \%)$ & $43(51.81 \%)$ & & $3(3.61 \%)$ & $75(90.36 \%)$ & $5(6.03 \%)$ & \\
\hline High school majors & & & 0.63 & & & & 0.236 \\
\hline Science & $32(47.76 \%)$ & $35(52.24 \%)$ & & $3(4.48 \%)$ & $6(91.04 \%)$ & $3(4.48 \%)$ & \\
\hline Social & $6(46.2 \%)$ & $7(53.8 \%)$ & & 0 & $12(92.30 \%)$ & $1(7.7 \%)$ & \\
\hline Language & $1(100 \%)$ & 0 & & 0 & $1(100 \%)$ & 0 & \\
\hline Vocational health & $9(47.36 \%)$ & $10(52.64 \%)$ & & 0 & $18(94,7 \%)$ & $1(5.3 \%)$ & \\
\hline Other VHS & $6(60 \%)$ & $4(40 \%)$ & & 0 & $9(90 \%)$ & $1(10 \%)$ & \\
\hline
\end{tabular}

\section{Coping Mechanism}

The majority of the coping mechanism at the level of moderately adequate $(\mathrm{n}=101$, mean $=22, \mathrm{SD}=25.8$ and range of scores 181-288) (Table 5). Coping mechanism on primary subscales which consists of 8 components, 7 of the majority are at the level of moderately adequate namely problem solving, cognitive restructuring, express emotions, problem avoidance, wishful thinking, self critism and social withdrawal with a mean value of the highest in problem solving (mean $=32.6$ ). While the majority of social support are at adequate levels. Similarly, the secondary subscales (problem focused engagement, emotion focused engagement, problem focused disengagement, emotion focused disengagement) and tertiary subscales (engagement and disengagement), all of its components at the level of moderately adequate with a mean value of the highest is problem focused engagement $($ mean $=64)$ and engagement $($ mean $=120.7)($ table 6$)$. Statistical analysis showed no significant differences in the level of coping mechanism based on demographic characteristics ( $\mathrm{p}$ value $=0.737 ; 0.34 ; 0.186$ and $0.236>\alpha=0.05$ ) (Table 4). 
Table 5 Coping Mechanism

\begin{tabular}{|c|c|c|c|c|c|}
\hline \multirow[t]{2}{*}{ Variables } & \multirow[t]{2}{*}{ Mean } & \multirow[t]{2}{*}{ SD } & \multicolumn{3}{|c|}{ Level } \\
\hline & & & Inadequate & $\begin{array}{c}\text { Moderately } \\
\text { adequate }\end{array}$ & Adequate \\
\hline Coping mechanism & 225 & 25.8 & 3 & 101 & 6 \\
\hline \multicolumn{6}{|c|}{ Table 6 Level of Coping subscale } \\
\hline \multirow{2}{*}{\multicolumn{2}{|c|}{ Coping subscale }} & \multicolumn{4}{|c|}{ Level of coping } \\
\hline & & Mean & Inadequate & $\begin{array}{l}\text { Moderately } \\
\text { adequate }\end{array}$ & Adequate \\
\hline \multirow[t]{8}{*}{ Primary subscales } & Problem solving & 32.6 & 0 & 60 & 50 \\
\hline & $\begin{array}{l}\text { Cognitive } \\
\text { restructuring }\end{array}$ & 31.1 & 2 & 84 & 24 \\
\hline & Express emotions & 26.5 & 24 & 79 & 7 \\
\hline & Social support & 30.6 & 11 & 35 & 64 \\
\hline & Problem avoidance & 24.83 & 35 & 73 & 2 \\
\hline & Wishful thinking & 29.8 & 8 & 77 & 25 \\
\hline & Self critism & 26.72 & 21 & 77 & 22 \\
\hline & Social withdrawal & 23 & 48 & 61 & 1 \\
\hline \multirow[t]{4}{*}{$\begin{array}{l}\text { Secondary } \\
\text { subscales }\end{array}$} & $\begin{array}{l}\text { Problem focused } \\
\text { engagement }\end{array}$ & 64 & 0 & 82 & 28 \\
\hline & $\begin{array}{l}\text { Emotion focused } \\
\text { engagement }\end{array}$ & 57 & 5 & 90 & 15 \\
\hline & $\begin{array}{l}\text { Problem focused } \\
\text { disengagement }\end{array}$ & 55 & 14 & 87 & 9 \\
\hline & $\begin{array}{l}\text { Emotion focused } \\
\text { disengagement }\end{array}$ & 50 & 30 & 78 & 2 \\
\hline \multirow[t]{2}{*}{ Tertiary subscales } & Engagement & 120.7 & 2 & 91 & 17 \\
\hline & Disengagement & 104 & 21 & 86 & 3 \\
\hline
\end{tabular}

\section{Academic stress in nursing students}

The majority of new nursing students experiencing academic stress at a low level. The cause of the highest stress due to academic factors, such as students complain of stress because of the many assignments and exams, erratic and long hours of study, lack of support from the university and late in submiting the assignment. Lowest cause is due to environmental factors that moving to a new environment and adjustment to new people / new friends. This is in line with research conducted by Hirsch that significant predictors of stress among university students is the complexity of the method of assessment, the level of difficulty of exams and assignments, daily overload of activities and the lack of time given to the task (Hirsch et al, 2015). Research by Prasad (2013) revealed that majority of students (51.7\%) had mild stress and $46.7 \%$ students had moderate stress and remaining $(1.7 \%)$ students had severe stress. Shiferaw (2015) research, $47.7 \%$ of nursing students of baccalaureate program in Jimma University were experience stress to cause the highest stress is intrapersonal factors due to high expectation from the self was, the new responsibility of life, lack of friend, financial problems, change in eating pattern and the least was due to change in sleep patterns. Interpersonal stressors were the second common source of stress brought on by high parental expectation, change in social activities, lack of cooperation from friends, disagreement with close ones and the least was lack of close or intimate friend. Environmental stressors were the third and academic factors were the least stressful. Al-Dubai (2011) study reported that there were 174 students 
(46.3\%) who reported having some or too much stress, whereas $179(47.6 \%)$ reported that they felt a little bit of stress, only 23 students $(6.1 \%)$ reported no stress. Worries of the future, difficulties financial, and academic life stressors were the most common among medical students in this study.

In this study, high stress levels experienced by the majority of male than female students. This contrasts with research by Kumar and Bhukar (2013), where stress was higher in girls in comparison to boys because of the fact that girls were expected to observe your social customs and restrictions in Indian society is comparatively more than boys. While the results of statistical tests in this study showed no significant difference in the level of stress based on demographic characteristics. These results are consistent with research conducted by Prasad (2013) that there was no significant association with the stress levels selected demographic variables (age, gender, religion, place of living, type of family, order of birth, economic support, hobbies, selection / choice of course, the medium of instructions in college).

Stress is a psychological response of individuals when confronted with things that are considered to exceed the limits, it is considered difficult to deal with and there the gap between the demands of the environment and the individual's ability to fulfill considered potentially harmful, threatening, harassing and uncontrolled or exceed the individual's ability to perform coping (Boyd, 2008). Stress can be unpleasant, perceived as a condition in which individuals experience anxiety, fear, worry, or anxiety (called distress). But stress can also be fun and an incredibly satisfying experience (Varcarolis \& Halter, 2010).

New students are prone to stress because they are in the final phase of adolescent development which at this stage would be a storm \& stress. This is in line with research conducted by Shiferaw (2015) that the first year students experienced more stress than students at fourth years. But studies in Malaysia instead showed that students in the second year was experiencing more stress than students in the first year (Liu et al, 2015). Source of the causes of stress in nursing students is academic, exams, workload, the pressure with a friend, financial demands, a new phase of development, fear of failure and difficult to cope with new social environment (Alzayyat, 2015).

Stress experienced by nursing students included in the category of academic stress arising from pressures to show outstanding achievement and excellence in academic competition conditions. It can be experienced by students at any level, both first-year and fourth years. The big difference in the level of stress and its causes in the above study, possibly because there are differences in the socio demographic background and the educational curriculum.

\section{Coping mechanism nursing students}

The majority of the student's coping mechanism at the level of moderately adequate. Coping mechanism on primary subscales which had the highest mean value is problem solving that students using behavioral and cognitive strategies that are designed to get rid of the source of stress by changing the situations that cause stress. While the lowest aspect is social withdrawal. This aspect reflects that people always blame themselves for the situation of selfcriticism. The highest mean value in the secondary subscales is problem focused engagement. This subscale includes both the problem solving and cognitive restructuring subscales. This aspect involves cognitive and behavioral strategies to change the situation or the meaning according to individual situations, coping effort is focused on its own stress situations. While at tertiary subscales highest mean value is engagement. This subscale includes problem solving, cognitive restructuring, social support and express emotions. The subscale reflects attempts by the individual to engage the individual in efforts to manage the stressful person/environment transaction. Through these coping strategies individuals engage in an active an ongoing negotiation with the stressful environment. 
Examples of problem solving used by students in this research is to change things to be better, concentrate on things or what will happen next, creating an action plan, addressing the subject matter, are trying to solve and solve the problem. While the form of social withdrawal undertaken by students is do not let others know what is perceived / experienced, spending time alone, never discuss with others and avoiding family and friends.

This is according to research conducted by Al-Zayyat and Al-Gamal (2014) that more nursing students to use problem solving coping mechanism. Research by Prasad (2013) showed that $86.7 \%$ students are having well coping strategies and $13,3 \%$ having average coping and there is no students with poor coping. Research by Shiferaw (2015) showed that majority of the students were using healthy coping strategies than unhealthy coping strategies. The common methods adopted by the study subjects were positive thinking such as, thinking how similar things were handled in the past, talking to parents, praying more than usual (relying on religious faith), use of a step by step approach to solve problem, and sharing of problems with friends. Research by Al-Dubai (2011) showed that the students used active coping strategies (active coping, religious coping, positive reframing, planning, and acceptance) more than avoidant strategies (denial, self-blame, and alcohol or substance use). But this study was in contradiction with study by Hirsch (2015) that found if most of the strategies used by the students in order to try and manage the emotional tension generated by the problem are those that focus on emotions.

The study also showed no significant differences in the level of coping mechanism based on demographic characteristics. These results are consistent with research Abasimi (2015) that there was no statistically significant difference in the reported levels of the various categories of stress among male and female students. Research Prasad (2013) that there was no significant association between coping mechanism with selected demographic variables such as age, gender, religion, place of living, type of family, order of birth, economic support, hobbies, selection / choice of course, the medium of instruction in college.

Individuals will perform coping behaviors in an effort to reduce stress. The process is not just a coping mechanism for coping incident involving ongoing transactions with the environment, and the process should be seen as a dynamic series. Coping shown by the individual or a person may vary depending on the problems encountered. When there is a condition that is full of stress, coping strategies used in an attempt to cope with threatening situations and regain balance. The use of appropriate coping will be able to solve the problem. Effective coping will cause individuals to be able to adapt. However, the use of ineffective coping strategies will lead to physiological changes manifested by changes in sleep patterns, decreased physical activity, and increased irritability that will affect the psychological health and social relationship (Sarafino, 2006; Hirsch, 2015) .

Coping mechanism used by nursing students of University of Muhammadiyah Malang was acceptable, that was problem focused coping. Problem focused coping, which is the effort to cope with stress by adjusting or changing the problems encountered and the surrounding environment that cause stress. Problem focused coping is aimed at reducing the demands of stressful situations or expand resources to cope. A person tends to use problem focused coping when they believe that the source or the demands of the situation can be changed. While emotion focused coping, which is the effort to cope with stress by regulating emotional responses in order to adapt to the impacts that will be caused by a condition or situation is considered stressful. Emotion focused coping is intended to control emotional responses to stressful situations. Appropriate coping strategies will be more directed to the problem focused coping, which is a strategy by dealing with the problem directly through the measures used to eliminate the sources of stress. Coping strategies that focus on the problem are effective for dealing with stressful situations. Nursing students who used coping strategies focused on resolving problems had lower means of stress compared to those who used strategies targeting emotions (Nasir \& Mufith, 2011; Hirsch, 2015). 


\section{CONCLUSION}

It can be concluded that the coping mechanism used by the new nursing students classified as appropriate, because they use more problem focused coping. However, it is advisable for the Faculty to teach stress management to the students since there are many students who have high levels of high stress, opened the counseling activities, disseminating information about how learning programs that will be undertaken by the new students of nursing for college later and reduce the academic load at the beginning of the semester because the students are still at the stage of adaptation. As for the next researcher to develop a longitudinal study design to determine the development level of stress and coping mechanism and interventions to reduce stress levels or to improve the coping mechanism to be better.

\section{REFERENCES}

Abasimi, E., Atindanbila, S., Mahamah, M.M., \& Gai, X, (2015). The Experience of Stress among Nursing Students in Nursing Training Colleges in Tamale, Ghana. International Journal of Psychology and Behavioral Sciences. Vol 5 (2): 89-97. DOI:10.5923/j.ijpbs.20150502.06

Al-Barrak, M.Y., El-Nady, M.T., \& Fayad, E.A, (2011). Sources of Stress as Perceived by Nursing Students at King Saud University. Med. J. Cairo Univ. Vol 79, No. 1: 541-553.

Al-Dubai, S.A.R., Al-Naggar, R.A., Alshagga, M.A., \& Rampal, K.G, (2011). Stress and Coping Strategies of Students in a Medical Faculty in Malaysia. Malaysian J. Med Sci. Vol 18 (3): 57-64.

Alzayyat, A. Obay, A.A \& Yahia M.A, (2015). Stress and Coping among Nursing Students during Their Practical Education in Psychiatric Settings: A Literature Review. Global Advanced Research Journal of Medicine and Medical Science. (ISSN: 2315-5159) Vol. 4(5) pp. 240-247, May, 2015. Available online http://garj.org/garjmms/index.htm.

Al-Zayyat, A.S \& Al-Gamal, E, (2014). Perceived Stress and Coping Strategies Among Jordanian Nursing Students During Clinical Practice in Psychiatric/Mental Health Courses. International Journal of Mental Health Nursing. Vol 23: 326-335. DOI: 10.1111/inm.12054.

Bamuhair, S.S., Al Farhan, A.I., Althubaiti, A., Agha, S., Rahman, S., \& Ibrahim, N.O, (2015). Sources of Stress and Coping Strategies Among Undergraduate Medical Students Enrolled in a Problem Based Learning Curriculum. Journal of Biomedical Education. Volume 2015, Article ID 575139. http://dx.doi.org/10.1155/2015/575139.

Boyd, M.A, (2008). Psychiatric Nursing Contemporary Practice. Fourth Edition. Philadelphia: Lippincott Williams and Wilkins.

Hirsch, C.D., Barlem, E.L.D., Barlem, J.G.T., Lunardi, V.L., \& Oliveira, A.C.C, (2015). Predictors of Stress and Coping Strategies Adopted by Nursing Students. Acta Paul Enferm. 28 (3): 224-229. DOI: http://dx.doi.org/10.1590/1982-0194201500038

Hirsch, C.D., Barlem, E.L.D., de Almeida, L.K., Barlem, J.G.T., Figueira, A.B., \& Lunardi, V.L, (2015). Coping Strategies of Nursing Students for Dealing with University Stress. Rev Bras Enferm. 2015: 68 (5): 501-508. DOI: http://dx.doi.org/10.1590/00347167.2015680503i.

Jobson. M.C \& Subhashini, R, (2016). The Effectiveness of Coping Strategy Training for Behavioural Modification among School Going Heart Defect Children after Surgery. The International Journal of Indian Psychology. Volume 3, Issue 4, No 64.

Kaneko, S \& Momino, K, (2015). Stress Factors and Coping Behaviors in Nursing Students During Fundamental Clinical Training in Japan. International Journal of Nursing \& Clinical Practices. Volume 2. DOI: http://dx.doi.org/10.15344/2394-4978/2015/138. 
Kumar, S \& Bhukar, J.P, (2013). Stress Level and Coping Strategies of College Students. Journal of Physical Education and Sports Management. Vol 4 (1): 5-11. DOI: 10.5897/JPESM12.001.

Labrague, L.J, (2013). Stress, Stressors and Stress Responses of Nursing students in a Government Nursing School. Health Science Journal. Vol 7, issue 4.

Liu, M., Gu Ken., Wong, T.K.S., Luo, M.Z., \& Chan, M.Y, (2015). Perceived Stress among Macao Nursing Students in the Clinical Learning Environment. International Journal of Nursing Sciences. Vol 2: 128-133.

Nasir, A \& Mufith, A, (2011). Dasar-Dasar Keperawatan Jiwa Pengantar dan Teori. Jakarta: Salemba Medika.

Olejnik, S. N. \& Holschuh, J. P, (2007). College rules! 2nd Edition How to study, survive, and succeed. New York: Ten Speed Press. [On-line]. Diakses dari: http://books.google.co.id/books?id=h_cfDji4V6YC\&pg=PA101\&dq=stress+academic \& $\mathrm{hl}=\mathrm{id} \& \mathrm{ei}=5 \mathrm{oezTK} 2 \mathrm{CJ}$ se3cOiYtKwI\&sa$=\mathrm{X} \&$ oi=book_result\&ct=result\&resnum $=6 \& \mathrm{ve}$ $\mathrm{d}=0 \mathrm{CD} 0 \mathrm{Q} 6 \mathrm{AEwBQ} \# \mathrm{v}=$ onepage\&q\&f$=$ false. Diakses 18 Nopember 2015.

Prasad, V., Suresh, A., Thomas, D.K., Pritty, M.K., Beebi, S., \& Multazin, V, (2013). The Level of Stress and Coping Mechanism Adopted by I Year B.S.c Mursing Students. Archives of Medicine and Health Sciences. Vol 1, Issue 1.

Sarafino, E.P, (2006). Health Psychology (5nd ed). New York: John Wiley and Sons.

Shaikh, B.T. Arsalan, K. Muhammad K, Hamza K, Kiran N, Nadia A,K \& Saadiya K, (2004). Students, Stress and Coping Strategies: a Case of Pakistani Medical School. Education for Health, Vol. 17, No. 3, November 2004, 346 - 353. DOI: $10.1080 / 13576280400002585$.

Singh, N \& Kohli, C. (2015). Stress Reaction and Coping Strategies Among Nursing Students in Delhi. Asian J. Nursing Edu and Research. 5 (2): April - June 2015. DOI: 10.5958/2349-2996.2015.00054.3

Shiferaw, H., Anand, S., \& Nemera, G, (2015). Stress and Coping Strategies among Generic B.S.c Nursing Students of JIMMA University, South West Ethiopia. International Journal of Recent in Multidisciplinary Research. Vol 2, Issue 07: 0511-0517.

Tobin, D.L, (2001). User Manual for the Coping Strategies Inventory. http://scholar.google.co.id/scholar_url?url=http://www.peersupport.edu.au/wpcontent/uploads/2014/08/Coping-Strategy-Indicator. Cited on 12 August 2015.

Varcarolis, E.M \& Halter, M.J, (2010). Foundation of Psychiatric Mental Health Nursing. Canada: Saunders Elsevier.

Yumba, W, (2010). Academic Stress: a Case of Undergraduate Students. https://www.divaportal.org/smash/get/diva2:556335/FULLTEXT01.pdf. Cited on 12 August 2015. 